\title{
$z$ calibration of the atomic force microscope by means of a pyramidal tip
}

\author{
Jensen, Flemming
}

Published in:

Review of Scientific Instruments

Link to article, DOI:

$10.1063 / 1.1143873$

Publication date:

1993

Document Version

Publisher's PDF, also known as Version of record

Link back to DTU Orbit

Citation (APA):

Jensen, F. (1993). $z$ calibration of the atomic force microscope by means of a pyramidal tip. Review of Scientific Instruments, 64(9), 2595-2597. https://doi.org/10.1063/1.1143873

\section{General rights}

Copyright and moral rights for the publications made accessible in the public portal are retained by the authors and/or other copyright owners and it is a condition of accessing publications that users recognise and abide by the legal requirements associated with these rights.

- Users may download and print one copy of any publication from the public portal for the purpose of private study or research.

- You may not further distribute the material or use it for any profit-making activity or commercial gain

- You may freely distribute the URL identifying the publication in the public portal

If you believe that this document breaches copyright please contact us providing details, and we will remove access to the work immediately and investigate your claim 


\title{
$z$ calibration of the atomic force microscope by means of a pyramidal tip
}

\author{
F. Jensen \\ Mikroelektronik Centeret, DTH, Building 345e, DK-2800 Lyngby, Denmark
}

(Received 22 March 1993; accepted for publication 12 May 1993)

\begin{abstract}
A new method for imaging the probe tip of an atomic force microscope cantilever by the atomic force microscope itself (self-imaging) is presented. The self-imaging is accomplished by scanning the probe tip across a sharper tip on the surface. By using a pyramidal probe tip with a very well-defined aspect ratio, this technique provides an excellent $z$-calibration standard for the atomic force microscope.
\end{abstract}

\section{INTRODUCTION}

The atomic force microscope (AFM), developed in 1986 by Binnig and co-workers, ${ }^{1}$ is a very promising new tool for investigating surfaces with high spatial resolution. Unlike its predecessor, the scanning tunneling microscope (STM), the AFM measuring is not restricted to conductive or semiconductive surfaces. This opens up to the study of a large variety of new areas-especially those involving measurements done in ambient air where inevitable oxide layers often form on the surfaces thus preventing STM investigations. Due to its large dynamical range, the AFM has been used to analyze surfaces and interfaces on many levels ranging from atomic resolution images of conductors, ${ }^{2}$ nonconductors, ${ }^{3}$ and molecular films ${ }^{4.5}$ to more technological applications such as imaging nanofabricated semiconductor structures, ${ }^{6,7}$ photoresist on semiconductors, ${ }^{8}$ and for thermomechanical writing on a polymer substrate. $^{9}$

Being a stylus technique, force microscopy does, however, suffer from the basic problem common to all techniques in this group: The image obtained is a convolution of the sample surface and the shape of the tip. As a result, a tip which is dull (low aspect ratio) compared to the surface features to be measured, will cause a rounding or give rise to some other distortion of sample protrusions or steps. When scanning atomically flat surfaces in contact (repulsive) mode with short ranging interaction force, this problem is of minor importance since the interaction region will be confined to the small assembly of outermost atoms at the end of the tip. In the case of a rough surface, however, or when performing measurements in noncontacting modes (using, e.g., magnetic or van der Waals forces) where the interaction forces have a longer range, a larger part of the tip participates in the interaction thus making the macroscopic shape of the tip important as well. In order to interpret the AFM image correctly it is therefore essential to deconvolve the shape of the tip from the image, i.e., one should somehow be able to measure the tip profile.

Another problem in connection with the AFM is finding a proper way to calibrate the $x, y$, and $z$ displacements of the piezoelectric transducer in the measuring range of interest. When measuring single-crystal surfaces with atomic resolution, the lateral calibration ( $x$ and $y$ ) can be obtained from the resolved surface lattice and the $z$ cali- bration can be achieved from single-layer steps. For measurements performed at larger measuring ranges, say from $100 \mathrm{~nm}$ to several $\mu \mathrm{m}$, it is however inadequate simply to extrapolate the calibration obtained in the atomic resolution regime since the piezo response is generally not linearly through the whole measuring range. Calibration of the response of piezoelements has previously been carried out by means of laser interferometry, ${ }^{10,11}$ a capacitance dilatometer, ${ }^{12}$ or by an inductive linear gauge. ${ }^{13} \mathrm{~A}$ general disadvantage of these methods is that they are rather complex to handle and therefore must be considered sort of one-time calibration--especially if the microscope is situated in an ultrahigh vacuum chamber. Furthermore, they must be considered to be indirect methods as they only calibrate part of the instrument (the piezoelement) and not the instrument itself during operation. A more convenient and direct way to calibrate the $x$ and $y$ response in the large scan range regime, is to scan a grid (possibly a double grid) with an appropriate lattice constant which can be manufactured, e.g., by means of $e$-beam lithography or holographically and calibrated using diffraction of laser light. There is, however, still a lack of a well-suited standard for the $z$ calibration of the instrument.

\section{BASIC IDEA}

In this letter, we introduce a new way to measure the tip profile and to apply this for a direct $z$ calibration of the AFM. The idea is to scan the probe tip which has a welldefined aspect ratio across a sharp tip on the sample with a larger aspect ratio. By doing this, the probe tip itself is imaged (self-imaging) and from the well-defined aspect ratio it is now possible to absolute calibrate the $z$ axis from a calibration of the $x$ and $y$ axes. In order to apply this method, two obvious problems have to be solved. Firstly, a cantilever with a probe tip which has a well-defined aspect ratio is required. Secondly, a sample with one (or several) sharp tip(s) has to be manufactured. Both of these problems have already been solved and are described in the literature.

Regarding the cantilever, Albrecht et al. ${ }^{14}$ presented a microfabrication process for producing $\mathrm{Si}_{3} \mathrm{~N}_{4}$ cantilevers with integrated pyramidal tips formed by using an etched pit on the $\mathrm{Si}(100)$ surface as a mold for a subsequent deposition of a $\mathrm{Si}_{3} \mathrm{~N}_{4}$ film. The pyramidal pit is formed by the use of an anisotropic etchant such as $\mathrm{KOH}$ [very low etch 


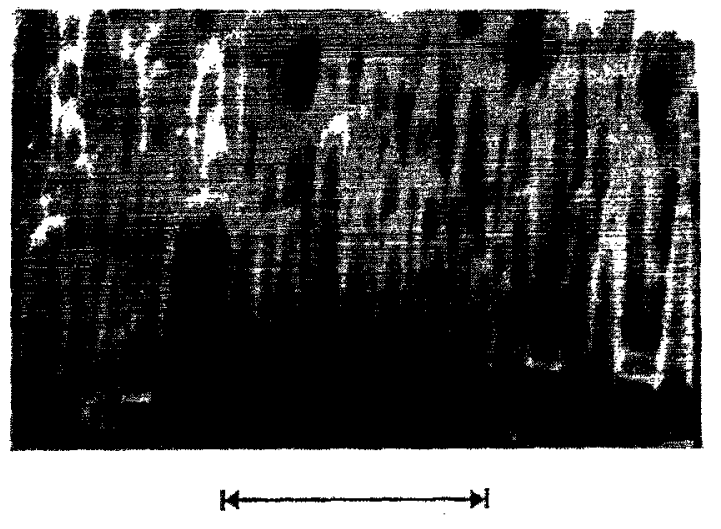

$0.5 \mu \mathrm{m}$

FIG. 1. SEM micrograph showing the InP surface after processing by means of reactive ion etching. The surface has a high density of $\approx 100$ nm-wide free-standing columns.

rate for (111) planes] which self-terminates when the volume of the removed $S i$ is bound by (111) planes. This procedure provides a nearly perfect pyramidal tip (well defined aspect ratio $=\sqrt{2}$ ) with a well-defined orientation with respect to the cantilever. Cantilevers of this type are now commercially available. ${ }^{15}$

Figure 1 displays a scanning electron microscope (SEM) micrograph of an InP surface with a high density of free-standing columns with vertical sidewalls (sharp tips). The typical dimensions of the columns are laterally of the order $\approx 100 \mathrm{~nm}$ and vertically of the order $\approx 500$ nm. This sample was prepared by means of reactive ion etching (RIE), which is a well-established plasma etching technique for fabricating small semiconductor devices and structures. ${ }^{16}$ In the present investigation, a parallel-plate reactor with a $13.6 \mathrm{MHz}$ rf excitation applied to the bottom electrode (cathode) and gases let in through a shower head of the top electrode provided the plasma. A methanebased plasma (mixture of $\mathrm{CH}_{4} / \mathrm{H}_{2}$ ) was used for the etching. ${ }^{16}$ During etching in this type of plasma, a polymeric film is deposited on the surface with a thickness which increases with an increase in the concentration of $\mathrm{CH}_{4}$ and a decrease in rf power. ${ }^{16}$ This polymeric film acts as an etch mask decreasing the etch rate dramatically in areas covered with the film. By choosing a suitable set of etching parameters, it is possible to obtain a micromasking effect leading to the surface shown in Fig. 1. In this case, the rf power was $100 \mathrm{~W}$ with $15 \mathrm{sccm} \mathrm{CH}_{4}$ and $50 \mathrm{sccm} \mathrm{H}_{2}$ at $15 \mathrm{~m}$ Torr for $72 \mathrm{~min}$.

\section{RESULTS AND DISCUSSION}

The AFM measurements were performed with a fully automated commercial instrument. ${ }^{17}$ The force detection part of the instrument combines the microfabricated cantilever ${ }^{15}$ with a beam-deflection sensor. ${ }^{18}$ Figure 2 shows a constant force topograph obtained when scanning an area of $2400 \times 2520 \mathrm{~mm}^{2}$ on the sample (Fig. 1) with a pyramidal probe tip. The topograph clearly reveals that with this sample we in fact are able to image the pyramidal

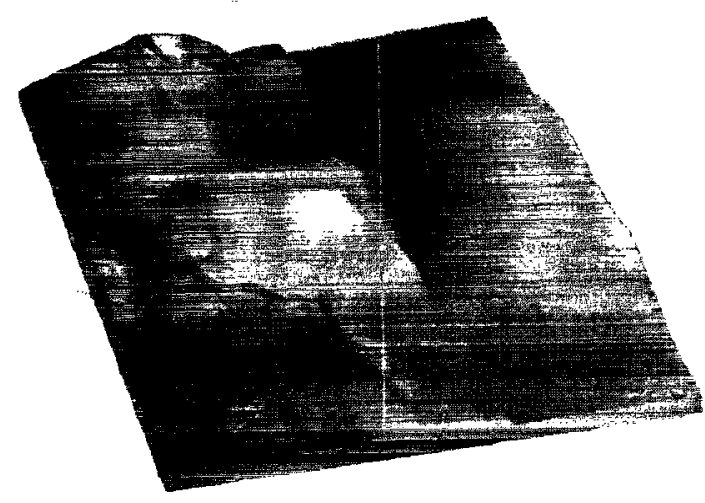

FIG. 2. AFM topograph $\left(2400 \times 2520 \mathrm{~nm}^{2}\right)$ obtained from scanning the pyramidal cantilever tip across the sharp surface columns shown in Fig. 1 . As the latter have almost vertical sidewalls, the resulting image shows the profile of the probe tip (self-imaging).

probe tip as described above. For the calibration of the $x$ and $y$ axis, we have used a grid made holographically with a lattice constant of $500 \pm 1 \mathrm{~nm}$.

Figure 3 presents a top view of the probe tip. A cross section of the tip through the inserted line is shown in the two insets. It appears that there is a certain limitation, determined by the finite size of the columns, to the degree of detail with which we can study the very end of the probe tip. It is possible, however, to find an upper limit for the radius of curvature of the probe tip. This is found to be less than $400 \AA$ in agreement with SEM investigations. ${ }^{14}$

From the linear part of the tip profile, determined by the (111) plane in bulk $\mathrm{Si}$, an absolute calibration of the $z$ axis can be achieved (provided that the $x$ and $y$ axes are calibrated) due to the well-defined aspect ratio. There is one problem though which must be considered first. If the probe tip is not tilted with respect to the surface normal, the measured aspect ratio $\alpha^{*}$ is simply determined by the aspect ratio of the (111) plane $\left[\tan \left(\Theta_{0}\right)\right.$ cf. Fig. 4] and the $z$-calibration factor $C_{z}$, i.e.,

$$
\alpha^{*}=\frac{\Delta Z_{i}^{*}}{\Delta X_{i}}=\frac{\tan \left(\Theta_{0}\right)}{C_{z}}=\frac{\sqrt{2}}{C_{z}},
$$

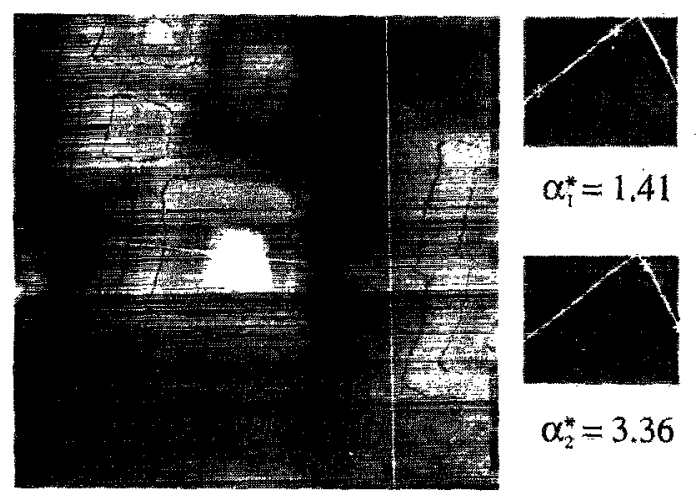

FIG. 3. Top view of the area shown in Fig. 2. The two insets show the slope measurements of two opposite sides of the pyramidal tip (cross section through the inserted white line). The black lines are curves of constant height. 


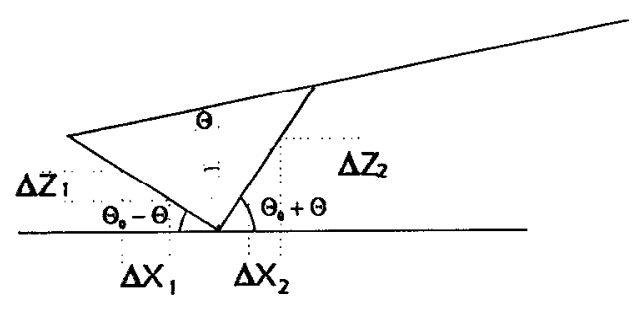

FIG. 4. Sketch of the pyramidal cantilever tip which is tilted an angle $\Theta$ with respect to the surface normal.

where the * indicates that the $z$ axis is not calibrated. In general the probe tip is tilted an angle $\Theta$ with respect to the surface normal which will influence the measured aspect ratio (see Fig. 4). This problem can be eliminated by measuring the aspect ratio for two opposite sides (index 1 and 2) of the pyramidal probe tip, whereby two equations with two unknowns, the $z$-calibration factor $C_{z}$ and the angle $\Theta$, are obtained. With the notation in Fig. 4 we get the following expressions:

$$
\begin{aligned}
& \alpha_{1}=C_{z} \alpha_{1}^{*}=\tan \left(\Theta_{0}-\Theta\right), \\
& \alpha_{2}=C_{z} \alpha_{2}^{*}=\tan \left(\Theta_{0}+\Theta\right),
\end{aligned}
$$

where $\alpha_{i}=\Delta Z_{i} / \Delta X_{i}(i=\{1,2\})$ is the aspect ratio after calibration of the $z$ axis. Using the addition formulas, (2a) and $(2 b)$ can be rewritten as a quadratic equation in $\tan (\Theta)(=x)$ :

$$
\begin{aligned}
& \left(\frac{\alpha_{1}^{*}}{\alpha_{2}^{*}}-1\right) x_{0} x^{2}+\left(\frac{\alpha_{1}^{*}}{\alpha_{2}^{*}}\left(x_{0}^{2}+1\right)+x_{0}^{2}+1\right) x \\
& +\left(\frac{\alpha_{1}^{*}}{\alpha_{2}^{*}}-1\right) x_{0}=0,
\end{aligned}
$$

where $x_{0}=\tan \left(\Theta_{0}\right)$.

Inserting the measured aspect ratios (see insets in Fig. 3) of $\alpha_{1}^{*}=1.41$ and $\alpha_{2}^{*}=3.36$ into Eq. (3) results in the solution $\Theta=11.4^{\circ} \pm 1.0^{\circ}$. Now, Eq. (2a) results in the calibration factor $C_{z}=0.68 \pm 0.04$. This kind of calibration can of course be performed for different $(x, y)$ values, thus giving an $(x, y)$ mapping of the $z$ response. Such a mapping is of course extremely useful for making a complete image correction.
In summary, we have presented a new technique for imaging the profile of an AFM tip. When using a probe tip with a well-defined aspect ratio, this technique provides a new method to calibrate the $z$ axis in a regime which is very important for many technological applications such as measurements of surface roughness, etc. The ease by which this calibration is performed is also appealing, as the AFM technique spreads out to a wide community of users.

\section{ACKNOWLEDGMENTS}

Pang $^{19}$ and Albrektsen ${ }^{20}$ are gratefully acknowledged for the preparation of the InP sample. This work was supported by the "MaterialeCenter for Mikroelektronik" (MCM).

${ }^{1}$ G. Binnig, C. F. Quate, and Ch. Gerber, Phys. Rev. Lett. 56, 930 (1986).

${ }^{2}$ G. Binnig et al., Europhys. Lett. 3, 1281 (1987).

${ }^{3}$ T. R. Albrecht and C. F. Quate, J. Appl. Phys. 62, 2599 (1987).

${ }^{4}$ J. Garnæs, D. K. Schwartz, R. Viswanathan, and J. A. N. Zasadzinski, Nature 357, 54 (1992).

${ }^{5}$ R. M. Overney, E. Meyer, J. Frommer, D. Brodbeck, R. Lüthi, L. Howald, H.-J. Güntherodt, M. Fujihira, H. Takano, and Y. Gotoh, Nature 359, 133 (1992).

${ }^{6}$ S. A. Chalmers, A. C. Gossard, A. L. Weisenhorn, S. A. C. Gould, B. Drake, and P. K. Hansma, Appl. Phys. Lett. 55, 2491 (1989).

${ }^{7}$ I.-H. Tan, D. G. Lishan, R. Mirin, V Jayaraman, T. Yasuda, C. B. Prater, E. L. Hu, J. E. Bowers, and P. K. Hansma, J. Vac. Sci. Technol. B 9, 3498 (1991).

${ }^{8}$ C. B. Prater, P. K. Hansma, I-H. Tan, D. G. Lishan, and E. L. Hu, J. Vac. Sci. Technol. B 10, 1211 (1992).

${ }^{9}$ H. J. Mamin and D. Rugar, Appl. Phys. Lett. 61, 1003 (1992).

${ }^{10}$ O. Albrektsen, L. L. Madsen, J. Mygind, and K. A. Mørch, J. Phys. E 22, 39 (1989).

${ }^{11}$ E. Riis, H. Simonsen, T. Worm, U. Nielsen, and F. Besenbacher, Appl. Phys. Lett. 54, 2530 (1989).

${ }^{12}$ S. Vieira, IBM J. Res. Develop. 30, 553 (1986).

${ }^{13}$ Millitron No. 1204IC, Feinpruf, Göttingen, Germany.

${ }^{14}$ T. R. Albrecht, S. Akamine, T. E. Carver, and C. F. Quate, J. Vac. Sci. Technol. A 8, 3386 (1990).

${ }^{15}$ Park Scientific Instruments, 1171 Borregas Ave. Sunnyvale, CA 94089.

${ }^{16}$ E. Andideh, I. Adesida, T. Brock, C. Caneau, and V. Keramidas, J. Vac. Sci. Technol. B 7, 1841 (1989), and references therein.

${ }^{17}$ Danish Micro Engineering (DME), Herlev, Denmark.

${ }^{18}$ G. Meyer and N. M. Amer, Appl. Phys. Lett. 53, 1045 (1988).

${ }^{19}$ Department of Electrical Engineering and Computer Science, University of Michigan, 1301 Beal Avenue, Ann Arbor, MI 48109-2122.

${ }^{20}$ TFL-Telecommunications Research Laboratory, Lyngsø Allé 2, DK 2970 Hørsholm, Denmark. 